\title{
Fine Finishing of Extended Surfaces of 316 L Stainless Steel Thin Plate with Magnetic Abrasives
}

\author{
Harnam Singh Farwaha ${ }^{1}$, Dharmpal Deepak ${ }^{2}$ and Gurinder Singh Brar ${ }^{3}$ \\ ${ }^{1}$ Department of Mechanical Engineering, Guru Nanak Dev Engineering College, Ludhiana, Punjab, India \\ ${ }^{2}$ Mechanical Engineering Department, Punjabi University, Patiala, Punjab, India \\ ${ }^{3}$ Department of Mechanical Engineering, National Institute of Technology, Srinagar, Uttarakhand, India \\ E-Mail: harnam16@gmail.com
}

\begin{abstract}
Some of the materials used in modern industries and industrial applications are difficult to finish with high degree of accuracy and minimal surface defects using conventional machining and polishing techniques. Stainless steel is one such widely used material that is ductile, tough and difficult to finish with traditional processes. This study aims to finish effectively the thin $316 \mathrm{~L}$ stainless steel plate using nontraditional technique as it is very difficult to finish using traditional technique. Response Surface Methodology approach for experimental design (Box-Behnken) is used for performing and analyzing the experimental work. BoxBehnken design is having the maximum efficiency for an experiment involving three factors and three levels. The experimental results indicate that the $316 \mathrm{~L}$ stainless steel plate can be successfully finished with diamond sintered magnetic abrasives. The process yields best results of Rotational Speed = 200RPM, Feed $=40 \mathrm{~mm} / \mathrm{sec}$ and Machining Time $=60 \mathrm{minutes}$ for PISF. The PISF was improved by $\mathbf{4 5 \%}$.
\end{abstract}

Keywords: Magnetic Abrasive Finishing, Non-Conventional machining process, Percentage Improvement In Surface Finish

\section{INTRODUCTION}

Stainless steels are emerging as advanced engineering materials because of their characteristics like anti oxidizing, anti corrosive and lustrous surface. Due to these characteristics they are widely applied in electronic, biochemical and medical instrumentation equipment. 316L stainless steel has been selected as work piece material for this research work. This material is widely used for medical implants, surgical tools, food preparation equipment, pharmaceuticals and marine applications. Chemical composition of 316L stainless steel is Carbon-0.03 max., Manganese-2.00 max. , Silicon-0.75 max. , Chromium16.00-18.00, Nickel-10.00-14.00, Molybdenum-2.00- 3.00, Phosphorus-0.045 max., Sulphur-0.03 max. , Nitrogen-0.10 max.Use of traditional machining techniques for finishing thin plates of stainless steel may lead to various defects like micro cracks, distortions on the work surfaces and errors in work piece geometry. Usually manual finishing is applied to obtain mirror like surface finish but, it is very time consuming and inefficient.

To resolve these problems, Magnetic abrasive finishing (MAF) has been used. It is a relatively new micro machining process that helps to achieve micro or nano level surface finish on various materials like stainless steel, aluminium and ceramics. It uses a controlled magnetic force of extremely small magnitude on ferromagnetic abrasive particles which are a conglomerate of abrasives and iron particles for the material removal. As it is possible to produce surface roughness of nanometre range using MAF on flat surfaces irrespective of the material hardness, finishing of very hard and brittle materials up to nanometre level is done with magnetic abrasive finishing. Shinmura et al. [1] conducted an experimental study on plane work pieces using the MAF process. They observed that with increase in finishing tim- e up to a particular limit, the surface roughness value decreases. Beyond that limit no further improvement in surface roughness value took place. They also concluded that stock removal and surface roughness improvement can be remarkably improved by adding the machining fluid (such as stearic acid, straight oil type of grinding fluid) to unbounded MAPs. Singh et al. [2] analyzed the performance of flexible magnetic brush and identified four parameters which magnetic field intensity (by varying current to the electromagnet), space between the work piece and magnetic poles, abrasive grain size (mesh number) and number of cycles. They conducted a number of experiments and used RSM and ANOVA and lead to the conclusion that magnetic flux density which depends upon the current to the electromagnet and machining gap is the main parameter followed by mesh number and number of cycles. To understand the material removal mechanism of MAF process, they used AFM and scanning electron microscope.

Literature survey reveals that MAF has been used on localised areas and the capability of MAF for finishing of extended areas on rods, plates and pipes has not been much explored. The present work has been undertaken to design \& develop a Magnetic abrasive finishing set up for finishing of extended plane surfaces and to finish thin sheets (3$5 \mathrm{~mm}$ ), as finishing of thin sheets is difficult by conventional method like grinding due to high temperature generated by large grinding forces.

\section{EXPERIMENTAL DESIGN}

\section{A. Process Principle}

Figure 1 shows a schematic of magnetic abrasive finishing process for finishing plane work pieces using a rotating magnetic pole system and linear feed motion of work piece. 
Magnetic abrasives introduced over the work piece surface are conglomerated at the finishing zone by a magnetic field, generating the finishing force against the upper surface of the work piece. In the process, magnetic abrasive particles introduced over the work piece are attracted by the magnetic field and bear on the upper surface of the work piece. These particles gets collected to form a flexible brush of magnetic abrasive particles which acts against the work piece due to the forces of attraction between the flexible brush and magnets. Indentations are formed on the work piece surface due to the finishing pressure. The centrifugal force and reciprocating force acting on the abrasive particles in flexible magnetic abrasive brush play a major role for cutting the work piece surface and formation of microchips. These controllable forces removes the particles from the surface and helps to attain a mirror like finish on the surface.

\section{B. Magnetic Abrasives}

These act as a cutting tool in magnetic abrasive finishing process. They consist of ferrous particles and non ferrous abrasives. In this study, the magnetic abrasives are formed by mixing Diamond powder (abrasive) (mesh size-250) 15 $\%$ by volume in Iron powder (mesh size-300) 85\%. The mixture were then compressed into cylindrical die and sintered in a specially designed furnace an $1100^{\circ} \mathrm{C}$ in the presence of $\mathrm{H}_{2}$ gas. Following the sintering process, the magnetic abrasives were crushed and separated to different sizes using sieving machine. Mesh size 140 of abrasives were used in this study. Iron particle and Diamond particle were difficult to separate during finishing since they cohered after sintering.

\section{Box-Behnken Design}

In this research work, Box-Behnken design approach is used. Box-Behnken design is having the maximum efficiency for an experiment involving three factors and three levels. The total number of experimental runs came out to be 17 and so, to complete the entire experimentation, same number experiments were performed in random order. Rotational speed of magnetic poles, feed of work piece and machining time were considered as experiment factors which would influence the surface roughness. After the data collection, analysis of variance (ANOVA) was applied to identify the significance of factors considered in this study. Finally the optimal conditions were generated.

\section{EXPERIMENTAL RESULTS AND DISCUSSION}

Figure 2 shows the photographic view of the experimental setup and the work conditions are shown in Table I. The 316 L stainless steel work piece was fixed on acrylic worktable during the magnetic abrasive finishing process. The magnetic poles were rotated and linear feed motion given to the work piece in this study. Selection of the independent variables is primarily based on the findings from the literature and pilot experimentation. Selected experimental factors were varied at three levels as listed in Table II \& Table III shows the experimental conditions. Surface roughness is measured at different positions and later the values were averaged to get more accurate results.

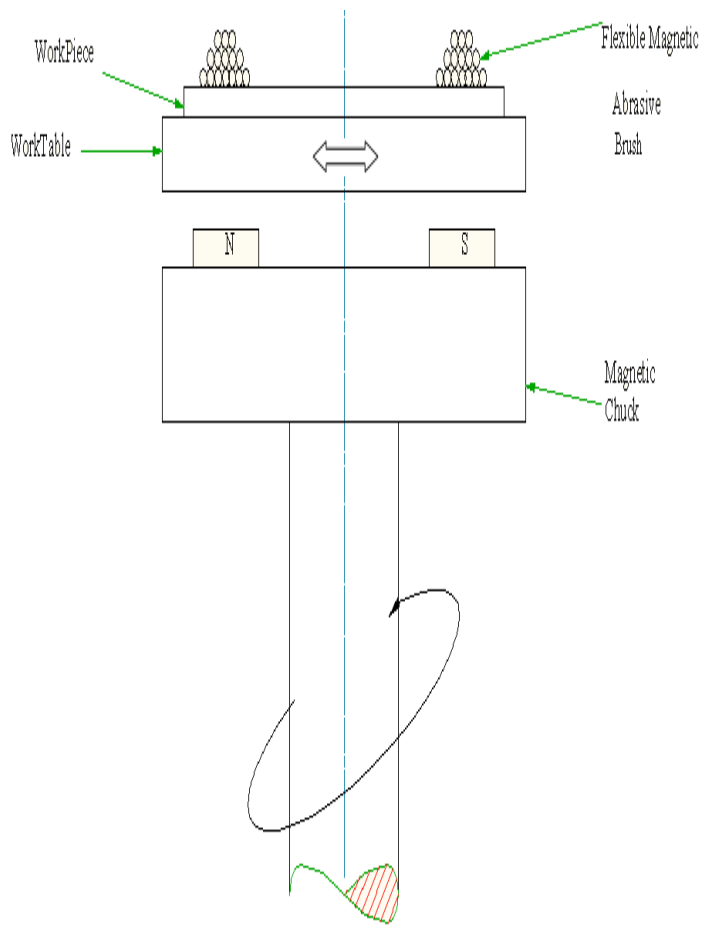

Fig. 1 Magnetic Abrasive Finishing Process

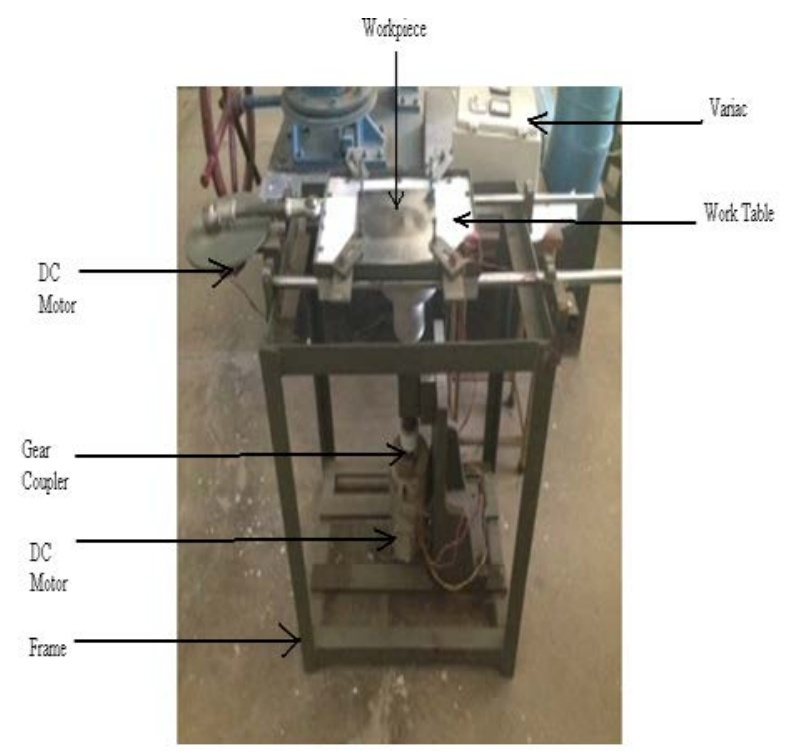

Fig. 2 Photographic view of Magnetic abrasive finishing setup

TABLE I EXPERIMENTAL CONDITIONS

\begin{tabular}{|l|l|}
\hline \multicolumn{1}{|c|}{ Item } & \multicolumn{1}{c|}{ Conditions } \\
\hline Work piece material & SUS 304 stainless steel \\
\hline Lubricant & Light oil( 5\% of quantity of abrasives) \\
\hline Abrasives & Fe + Diamond \\
\hline Magnetic Flux Density & 6000 Gauss \\
\hline
\end{tabular}


TABLE II EXPERIMENTAL FACTORS AND LEVELS

\begin{tabular}{|l|c|c|c|}
\hline \multicolumn{1}{|c|}{ Factor } & Level1 & Level2 & Level3 \\
\hline Rotational speed of poles (rpm) & 100 & 150 & 200 \\
\hline Feed of work piece (mm/sec) & 30 & 35 & 40 \\
\hline Machining time (minutes) & 30 & 60 & 90 \\
\hline
\end{tabular}

TABLE III EXPERIMENTAL RESULTS AND CALCULATED PISF

\begin{tabular}{|c|c|c|c|c|}
\hline $\begin{array}{c}\text { Sr } \\
\text { No. }\end{array}$ & $\begin{array}{c}\text { Rotational } \\
\text { Speed of poles } \\
\text { (rpm) }\end{array}$ & $\begin{array}{c}\text { Feed of } \\
\text { work piece } \\
\text { (mm/sec) }\end{array}$ & $\begin{array}{c}\text { Machining } \\
\text { time } \\
\text { (minutes) }\end{array}$ & PISF \\
\hline 1 & 100 & 30 & 60 & 17.50 \\
\hline 2 & 100 & 35 & 30 & 14.25 \\
\hline 3 & 200 & 30 & 60 & 23.75 \\
\hline 4 & 200 & 40 & 60 & 45.00 \\
\hline 5 & 100 & 35 & 90 & 23.75 \\
\hline 6 & 150 & 35 & 60 & 32.75 \\
\hline 7 & 100 & 40 & 60 & 36.50 \\
\hline 8 & 150 & 35 & 60 & 31.00 \\
\hline 9 & 150 & 30 & 30 & 05.00 \\
\hline 10 & 150 & 40 & 30 & 35.00 \\
\hline 11 & 200 & 35 & 30 & 20.00 \\
\hline 12 & 150 & 35 & 60 & 31.50 \\
\hline 13 & 150 & 40 & 90 & 30.00 \\
\hline 14 & 150 & 30 & 90 & 26.25 \\
\hline 15 & 200 & 35 & 90 & 32.75 \\
\hline 16 & 150 & 35 & 60 & 31.00 \\
\hline 17 & 150 & 35 & 60 & 31.50 \\
\hline
\end{tabular}

TABLE IV ANOVA FOR PROCESS PARAMETERS

\begin{tabular}{|c|c|c|c|c|c|c|}
\hline \multicolumn{7}{|c|}{ Analysis of variance table [Partial sum of squares - Type III] } \\
\hline Source & $\begin{array}{l}\text { Sum of } \\
\text { Square } \\
\text { s }\end{array}$ & df & $\begin{array}{l}\text { Mean } \\
\text { Squa } \\
\text { re }\end{array}$ & $\begin{array}{l}\text { F } \\
\text { Value }\end{array}$ & $\begin{array}{l}\text { p-value } \\
\text { Prob }>\text { F }\end{array}$ & \\
\hline Model & 226.77 & 9 & 25.20 & 93.17 & $<0.0001$ & $\begin{array}{l}\text { signifi } \\
\text { cant }\end{array}$ \\
\hline $\begin{array}{l}\text { A- } \\
\text { Rotational } \\
\text { Speed }\end{array}$ & 17.40 & 1 & 17.40 & 64.36 & $<0.0001$ & \\
\hline B-Feed & 109.52 & 1 & $\begin{array}{l}109.5 \\
2\end{array}$ & 404.99 & $<0.0001$ & \\
\hline $\begin{array}{l}\text { C- } \\
\text { Machining } \\
\text { Time }\end{array}$ & 29.65 & 1 & 29.65 & 109.62 & $<0.0001$ & \\
\hline Residual & 1.89 & 7 & 0.27 & & & \\
\hline Cor Total & 228.66 & 16 & & & & \\
\hline
\end{tabular}

The results were obtained in the form of surface roughness values and were used to calculate PISF. The obtained results were then analysed with ANOVA. In Box-Behnken design, the process yields best results of Speed $(A)=200 R P M$, Feed $(B)=40 \mathrm{~mm} / \mathrm{sec}$, Machining Time $(C)=60$ minutes for PISF. The Feed had a predominant effect on the percentage improvement in surface finish as shown in fig.3.

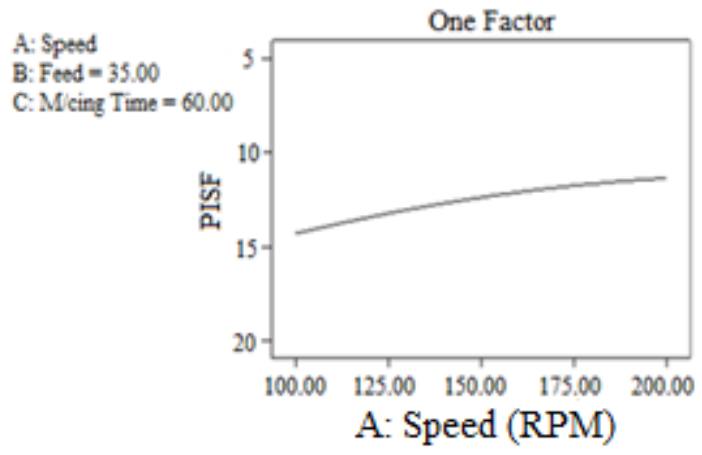

(a)

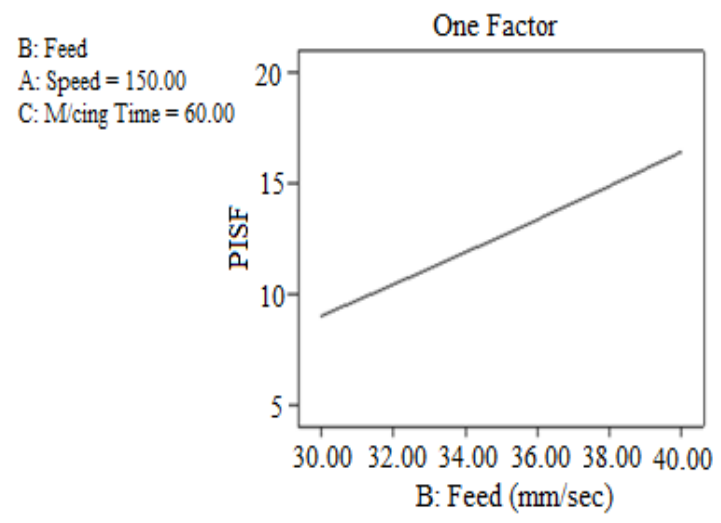

(b)

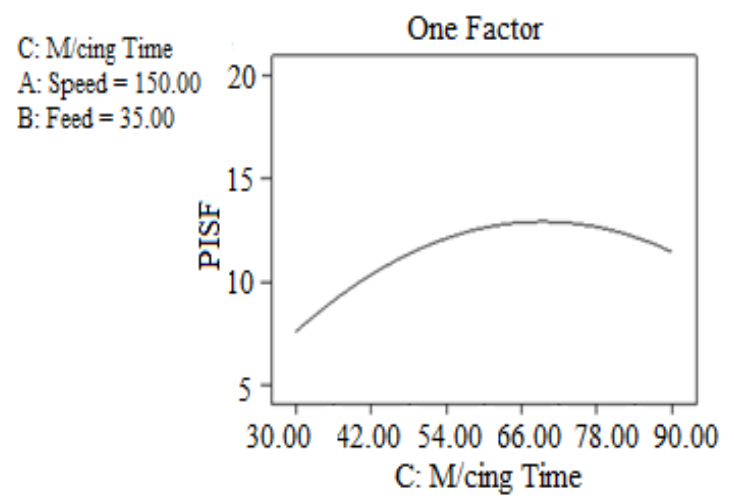

(c)

Fig. 3 Influence of parameters on magnetic abrasive finishing (PISF) of 316L stainless steel.

Mitutoyo (SJ-410) surface roughness tester having a least count of $0.001 \mu \mathrm{m}$ (cut off length $=0.8 \mathrm{~mm}$ ) was used to study the effect of abrasive behavior on work piece and to view the uniformity in surface roughness. The surface profile of scratched surface, generated by grinding is shown in the figure 4(a). The result of the surface produced after the magnetic abrasive finishing is shown in figure 4(b). This profile indicates that the peaks and valleys are reduced to greater extent leading to higher surface finish. These Figures reveals that the finished surface was quite smoother than before, indicating that the magnetic abrasive finishing process is very useful to improve the surface roughness of $316 \mathrm{~L}$ stainless steel. 


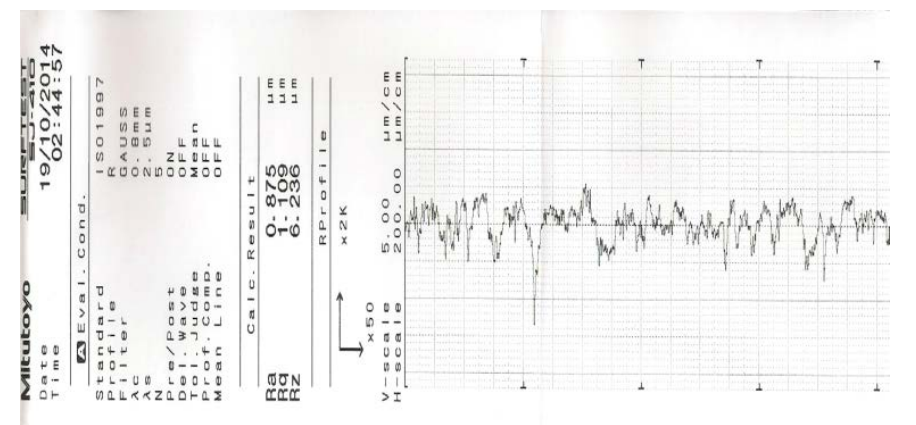

(a)

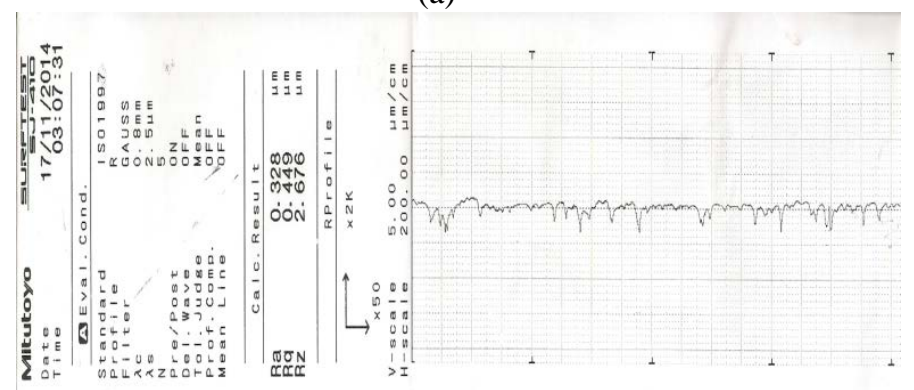

(b)

Fig. 4 Surface profile of workpiece (a) before magnetic abrasive finishing (b) after magnetic abrasive finishing.

\section{CONCLUSIONS}

In this study, magnetic abrasive finishing was performed on 316 L stainless steel thin plates and Box-Behnken experimental design \& ANOVA was applied to evaluate the parameters effect on the surface roughness. The results can be summarized as follows:

1. New designed set up was successfully used to cover extended areas of thin sheets with magnetic abrasive finishing.

2. The process yields best results of Speed $(A)=200 R P M$, Feed $(B)=40 \mathrm{~mm} / \mathrm{sec}$, Machining Time $(\mathrm{C})=60$ minutes for PISF. From ANOVA, it was concluded that the feed of work piece contributes maximum, as followed by machining time and rotational speed of poles. As compared to the surface finish obtained by using conventional surface grinding, the work piece surface finish was improved $45 \%$ by using Magnetic Abrasive Finishing.

\section{REFERENCES}

[1] T. Shinmura, K. Takajava and E. Hatano, "Study on Magnetic Abrasive Process - Application to Plane Finishing”, Bulletin of Japan Society of Precision Engineering, Vol. 19, No. 4, pp. 289-291, 1985.

[2] L. Singh, S. Singh and P.S. Mishra, "Performance of abrasives used in magnetically assisted finishing: a state of the art review", 2010

[3] C.T. Lin, L.D. Yang and H.M. Chow, "Study of magnetic abrasive finishing in free form surface operations using Taguchi method," International journal of Advance Manufacturing Technology, Vol. 34, pp.122-130, 2007.

[4] B. Girma, S.S. Joshi, M.V.G.S Raghuram and R. Balasubramaniam, "An Experimental analysis of Magnetic Abrasive finishing of plane surfaces,” Machining Science and Technology, Vol.10, pp.323-340, 2007.

[5] J.S. Kwak and T.K. Kwak, "Parameter optimization in Magnetic Abrasive Polishing for Magnesium Plate," 2nd International conference on Computer Engineering and Technology, Vol. 5, pp. 544-547, 2010.

[6] Lakhvir Singh, Khangura Sehijpal Singh and PS Mishra, "Performance of abrasives used in magnetically assisted finishing: A state of the art review," International Journal of Abrasive Technology, Vol. 3, pp. 215-227, 2010.

[7] V.K. Jain, P Kumar, P.K. Behra and S.C. Jayswal, "Effect of working gap and circumferential speed on the performance of magnetic abrasive finishing process,” Wear, Vol. 250, pp. 384-390, 2001.

[8] G.Z Kremen, E.A Elsayed and V.I. Rafalovich, "Mechanism of Material Removal in Magnetic Abrasive Process and Accuracy of Machining," International Journal of Production Engineering, Vol. 34, pp. 2629-2638, 1996.

[9] V.K. Jain, V. Raghuram and R. Komanduri, "Analysis of surface texture generated by a flexible magnetic abrasive brush,” wear, Vol. 259, pp. 1254-1261, 2005.

[10] M. Givi, A.F. Tehrani and A. Mohammadi, "Polishing of aluminum sheets with magnetic abrasive finishing method," International Journal of advanced manufacturing technology, Vol. 61, No. 9-12, pp. 989-998, 2011. 